\title{
Pirâmide alimentar para gestantes eutróficas de 19 a 30 anos
}

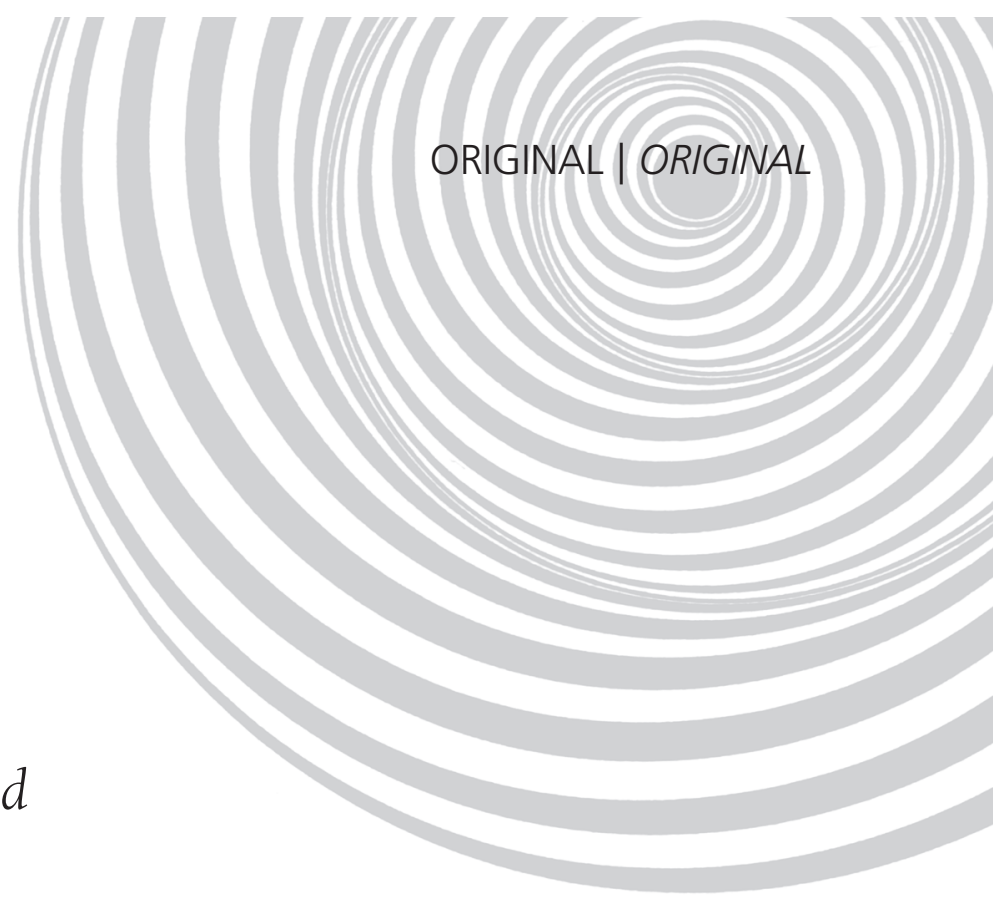

Franklin DEMÉTRIO'

RE S U M O

\section{Objetivo}

O objetivo deste estudo foi desenvolver uma pirâmide alimentar adaptada para as gestantes eutróficas na faixa etária de 19 a 30 anos, fundamentada nas diretrizes do guia alimentar para a população brasileira.

\section{Métodos}

A construção da pirâmide alimentar foi baseada em dois planos alimentares (2 188kcal referentes ao primeiro trimestre gestacional e $2502 \mathrm{kcal}$ para o segundo e terceiro trimestres gestacionais) calculados segundo recomendações para esse grupo.

\section{Resultados}

A distribuição percentual dos macronutrientes no plano alimentar proposto para o primeiro trimestre é de: $12 \%$ de proteínas, $62 \%$ de carboidratos e $26 \%$ de lipídeos. No segundo e terceiro trimestres gestacionais os percentuais obtidos são de: $11 \%$ para proteínas, $60 \%$ para carboidratos e $29 \%$ para lipídeos. As porções e os equivalentes foram estabelecidos a partir de adaptações do total energético de cada alimento obtido por Philippi et al. e disponível no guia alimentar para a população brasileira. Os alimentos estão organizados em oito grupos na pirâmide alimentar, independentemente do período gestacional, variando apenas a quantidade de porções recomendada.

\section{Conclusão}

Espera-se que a pirâmide alimentar desenvolvida seja útil aos profissionais de saúde na atenção pré-natal, favoreça a orientação alimentar e nutricional e contribua para promover a adequação do estado de nutrição e saúde da gestante eutrófica, além de contribuir também para reduzir a ocorrência de baixo peso ao nascer, prematuridade e macrossomia.

Termos de indexação: Gestantes. Guias alimentares. Necessidades nutricionais. Nutrição pré-natal.

\footnotetext{
1 Universidade Federal da Bahia, Escola de Nutrição. Av. Araújo Pinho, 32, Canela, 40110-150, Salvador, BA, Brasil. Correspondência para/Correspondence to: F. DEMÉTRIO.E-mails: <franklindemetrio@ufba.br>; <franklindemetrio@yahoo.com.br>.
} 


\section{A B S T R A C T}

\section{Objective}

This study aimed at developing a food guide pyramid for well-nourished pregnant women aged 19 to 30 years based on the food guide for the Brazilian population.

\section{Methods}

This food guide pyramid was constructed around two food plans: 2,188kcal for the first trimester of pregnancy and $2,502 \mathrm{kcal}$ for the second and third trimesters, calculated according to the recommendations for this population.

\section{Results}

The percentage distributions of macronutrients proposed for the first trimester are: 12\% proteins, $62 \%$ carbohydrates and $26 \%$ lipids. The percentages proposed for the second and third trimesters are: $11 \%$ proteins, $60 \%$ carbohydrates and 29\% lipids. The servings and their equivalents were established by adapting the total energetic content of each food item obtained by Philippi et al., available in the food guide for the Brazilian population. The foods were arranged into eight groups in the food guide pyramid, regardless of trimester of pregnancy; only the recommended number of servings vary.

\section{Conclusion}

Hopefully, this food guide pyramid will be useful for prenatal care providers, promote food and nutrition education, maintain the correct nutritional and health status of well-nourished pregnant women and contribute to reduce the rates of low birth weight, prematurity and macrosomia.

Indexing terms: Pregnant women. Food guide. Nutritional requirements. Prenatal nutrition.

\section{N T R O D U Ç Ã O}

A gestação é uma fase de importância fisiológica na vida da mulher e demanda cuidados essenciais, principalmente sob a óptica da assistência à saúde e à nutrição. Do ponto de vista nutricional, ocorrem mudanças no metabolismo de todos os nutrientes, que requerem ajustes fisiológicos continuados ${ }^{1}$. A competência para a realização desses ajustes compatíveis com o estado de saúde e nutrição materno-fetal depende de fatores relacionados ao estado nutricional pré-gestacional materno, de fatores genéticos, estilo de vida e comportamento materno'. O êxito desses ajustes resulta no adequado desenvolvimento e crescimento fetal. Nesse sentido, os níveis de nutrientes nos tecidos e líquidos corpóreos estão alterados para atender às mudanças fisiológicas, que se expressam na expansão do volume sanguíneo, nas alterações cardiovasculares, nas mudanças funcionais do sistema gastrointestinal, respiratório e na função renal ${ }^{2,1}$.

No contexto das alterações bioquímicas, podem ser registradas as modificações nos níveis das proteínas totais e dos lipídeos plasmáticos. No que diz respeito aos micronutrientes, registram-se concentrações séricas diminuídas de ferro ${ }^{3}$, ácido ascórbico ${ }^{4}$ e ácido fólico ${ }^{5}$.

Assim, na gestação, o atendimento das demandas nutricionais maternas tem influência no adequado ganho ponderal gestacional e no resultado obstétrico que se expressa no peso ao nascimento e na idade gestacional ao nascer ${ }^{6}$.

Vários estudos desenvolvidos nas últimas duas décadas em diversos países, inclusive no Brasil, indicam que o peso pré-gestacional e ganho ponderal durante a gestação correlacionam-se positivamente com o crescimento fetal ${ }^{3,7}$.

O ganho inadequado de peso durante a gestação pode comprometer o crescimento do feto, o peso adequado ao nascer, além de aumentar o risco de prematuridade ${ }^{8,9}$. Na mesma linha, tem sido levantada a hipótese de que tanto o retardo no crescimento intrauterino quanto a macrossomia podem contribuir para o desenvolvimento de obesidade, hipertensão arterial, resistência insulínica, síndrome metabólica e morbimortalidade cardiovascular na vida adulta ${ }^{10}$. 
Segundo a Organização Mundial da Saúde (OMS) ${ }^{11}$, mulheres que iniciam a gravidez com Índice de Massa Corporal (IMC) na faixa de normalidade $\left(18,5-24,9 \mathrm{~kg} / \mathrm{m}^{2}\right)$ e têm ingestão energética que supra as necessidades nutricionais requisitadas durante a fase gestacional, garantem o ganho de peso ideal e o desenvolvimento e crescimento adequados do concepto.

Por outro lado, as mulheres que iniciam a gravidez com baixo peso (IMC $<18,5 \mathrm{~kg} / \mathrm{m}^{2}$ ) assim como aquelas com sobrepeso (IMC no intervalo de $25,0-29,9 \mathrm{~kg} / \mathrm{m}^{2}$ ) e/ou obesidade (IMC $\geq 30 \mathrm{~kg} / \mathrm{m}^{2}$ ) podem incorrer em gestação com resultado insatisfatório ${ }^{11}$. As evidências indicam também que gestantes com estatura abaixo de $150 \mathrm{~cm}$, idade nos extremos do ciclo reprodutivo, isto é, menor que 19 anos ou superior a 30 anos e gravidez gemelar ou com morbidades associadas requerem acompanhamento específico e frequente dos profissionais de saúde no âmbito dos programas de atenção à gestante, com o objetivo de evitar o desfecho inadequado da gravidez $z^{2,12-15}$. Entende-se também que as gestantes na faixa etária de 19 a 30 anos com diagnóstico antropométrico pré-gravídico de eutrofia também merecem atenção especial dos programas de atenção pré-natal. Apesar de seu estado nutricional inicial não oferecer riscos para o desenvolvimento fetal, faz-se necessário manter o seu estado de saúde e nutrição adequado no transcorrer da gravidez para garantir o desenvolvimento e crescimento fetal satisfatórios.

Nesse sentido, alimentação e estilo de vida saudáveis são estratégias que inspiram as ações governamentais voltadas à política de segurança alimentar e nutricional e à prevenção de agravos à saúde da população brasileira, incluindo a população materno-infantil, a fim de prevenir os agravos advindos da alimentação inadequada nesse ciclo de vida ${ }^{16}$.

Recentemente, o Ministério da Saúde ${ }^{16}$, utilizando-se das evidências acumuladas nos últimos 50 anos, documentou, em forma de guia alimentar, as primeiras diretrizes alimentares oficiais para a população brasileira. No entanto, até o presente momento não consta na literatura consultada um guia alimentar específico para gestantes, estratégia que pode se mostrar eficaz na assistência alimentar e nutricional desse grupo. Por isso, apresenta-se um modelo no formato de pirâmide alimentar para educação alimentar e nutricional nesse ciclo da vida, tomando como parâmetro aquele apresentado por Philippi et al. ${ }^{17}$. Esse modelo tem sido catalogado como experiência bem-sucedida no que se refere à orientação e promoção de práticas alimentares saudáveis ${ }^{17,18}$.

Mediante as razões apontadas, torna-se relevante o desenvolvimento de uma pirâmide alimentar adaptada às gestantes eutróficas de 19 a 30 anos, baseada nas diretrizes para a promoção de sistemas alimentares saudáveis ${ }^{16}$, podendo complementar as informações já disponíveis no guia alimentar para a população brasileira.

\section{M É T O D OS}

O desenvolvimento da pirâmide alimentar adaptada para gestantes eutróficas se baseou, inicialmente, no levantamento bibliográfico em bases de dados eletrônicos e não eletrônicos com a finalidade de identificar estudos nacionais e internacionais, publicados no período de 1992 a 2006, que abordassem o desenvolvimento de guia alimentar para gestantes. As bases eletrônicas consultadas foram: Scientific Eletronic Library On-line (SciELO), Literatura Latino-Americana e do Caribe em Ciências da Saúde (Lilacs) e Medical Literature Analysis and Retrieval System Online (MedLine) da National Library of Medicine, utilizando-se dos termos em português: gestantes, nutrição pré-natal, guias alimentares, pirâmide alimentar, necessidades nutricionais e seus correspondentes em inglês: pregnant women, prenatal nutrition, food guide, food guide pyramid, nutritional requirements. Consultas em livros, manuais técnicos, dissertações e revistas científicas compuseram a base de dados não eletrônicos.

O segundo passo metodológico se constituiu no cálculo das necessidades nutricionais. Para 
tanto, assumiu-se o padrão da "mulher-tipo" segundo Martins" ${ }^{19}$, como base para o cálculo da taxa metabólica basal da gestante eutrófica. Para esse fim, utilizou-se o peso pré-gestacional da mulher-referência ${ }^{19}$ de modo a realizar o cálculo da necessidade calórica e proteica, conforme recomendações ${ }^{11}$.

A "mulher-tipo" ou mulher-referência, segundo Martins ${ }^{19}$, tem de 20 a 39 anos de idade, mede $156 \mathrm{~cm}$ de altura e pesa $55 \mathrm{~kg}$. É eutrófica $\left(I M C=22,63 \mathrm{~kg} / \mathrm{m}^{2}\right)$ e se ocupa 8 horas por dia em atividades do lar ou qualquer outra atividade leve.

A estimativa do Gasto Energético (GE) da "mulher-tipo" foi realizada com base na equação proposta pela FAO/OMS/UNU"1, a qual leva em conta o sexo, a idade e o peso do indivíduo para cálculo da Taxa Metabólica Basal (TMB) e determina que essa taxa seja multiplicada por um fator de atividade física ( $f a$ ). Neste trabalho, considerou-se o fator atividade de 1,56 como indicativo de atividade leve para a "mulher-tipo" 11,2,19.

Utilizou-se o método da FAO/OMS ${ }^{11}$ para cálculo do gasto energético da "mulher-tipo" em virtude de ser um dos mais empregados para se estimar as necessidades energéticas de indivíduos ou de coletividades, apesar do relatório da Food and Agriculture Organization of the United Nations (FAO) apontar para a dificuldade de se utilizarem os valores referentes às recomendações baseando-se em população para expressar a real necessidade de indivíduos ${ }^{20}$.

Baseada na conformação da "mulher-tipo" e a partir da equação usada para cálculo da TMB proposta pela $\mathrm{FAO} / \mathrm{OMS}^{11}$ para indivíduos do sexo feminino com idade entre 18 e 30 anos, obteve-se: $\mathrm{TMB}=14,7$ (constante fixada com base em calorimetria indireta realizada em indivíduos saudáveis do sexo feminino) $\times \mathrm{P}$ (peso em $\mathrm{kg}$ ) +496 (constante fixada com base em calorimetria indireta realizada em indivíduos saudáveis do sexo feminino), logo:

$\mathrm{TMB}=14,7 \times \mathrm{P}$ (peso da mulher-referência $\mathrm{em} \mathrm{kg)}+496$

$$
\begin{aligned}
& \mathrm{TMB}=14,7 \times 55+496 \\
& \mathrm{TMB}=1305 \mathrm{kcal}
\end{aligned}
$$

A partir do valor da TMB encontrado para a "mulher-tipo", calculou-se o seu gasto energético conforme preconizado pela FAO/OMS"11. Assim, tem-se que:

$$
\begin{aligned}
& \mathrm{GE}=\mathrm{TMB} \times \mathrm{fa} \text { (fator atividade) } \\
& \mathrm{GE}=1305 \times 1,56 \\
& \mathrm{GE}=2035 \mathrm{kcal}
\end{aligned}
$$

Dessa maneira, encontrou-se um gasto energético pré-gestacional diário de $2035 \mathrm{kcal}$ para a "mulher-tipo". Entretanto, pelo fato de as exigências energéticas da mulher estarem aumentadas na gestação devido principalmente à elevação do metabolismo basal em consequência da síntese acelerada de tecidos (fetal, placentário, uterino, mamário e de reserva materna), do aumento da massa de tecido metabolicamente ativo e do trabalho cardiorrespiratório ${ }^{2,11}$, foi necessário incrementar ao seu GE (2 035kcal) uma suplementação diária de caloria e proteína com intuito de promover o ganho ponderal materno-fetal preconizado para cada trimestre gestacional ${ }^{8}$.

Com base no custo energético gestacional de $80000 \mathrm{kcal}$ estimado pela FAO/OMS ${ }^{11}$, associado a um ganho de peso gestacional total preconizado em $12,5 \mathrm{~kg}$ e no peso do recém-nascido de 3,3kg e com menores índices de complicações na gravidez e no parto ${ }^{2}$, avaliou-se que para atingir esses parâmetros são gastos $80000 k c a l$ durante todo o período gestacional ${ }^{11}$. Adotou-se, ainda, que para cada $1 \mathrm{~kg}$ de peso a ser ganho durante o período gestacional, é requerido o adicional energético de $6400 \mathrm{kcal}^{11,2}$.

Para o cálculo do adicional energético diário referente a cada trimestre gestacional tomou-se como base as necessidades pré-gestacionais da mulher referência e considerou-se uma gestação a termo (39 semanas), não gemelar e com ganho médio total de peso de $13,75 \mathrm{~kg}$ no final da gestação, baseado no intervalo de ganho ponderal $(11,5 \mathrm{~kg}$ a $16,0 \mathrm{~kg})$ preconizado pelo Institute of Medicine $(\mathrm{IOM})^{8}$ para gestantes com diagnóstico antropométrico pré-gestacional de eutrofia (IMC entre $18,5 \mathrm{~kg} / \mathrm{m}^{2}$ a $\left.24,9 \mathrm{~kg} / \mathrm{m}^{2}\right)^{11}$. 
O custo calórico gestacional total para a gestante eutrófica tomada como referência foi estimado em $88000 \mathrm{kcal}$ a partir do ganho ponderal gestacional total programado de $13,75 \mathrm{~kg}^{11,2}$.

Para o processamento do cálculo das necessidades nutricionais por trimestre de gestação, foram adotados os procedimentos descritos a seguir:

a) O cálculo do adicional energético diário referente ao primeiro trimestre gestacional (até a $13^{\mathrm{a}}$ semana de gestação) foi realizado com base no ganho ponderal de $1,6 \mathrm{~kg}(0,123 \mathrm{~kg} / \mathrm{semana})$ recomendado para esse período para gestantes com diagnóstico antropométrico pré-gravídico de eutrofia ${ }^{8}$. Assim, se para cada $1 \mathrm{~kg}$ de peso a ser ganho pela gestante, o adicional energético requerido é de $6400 \mathrm{kcal}^{11}$, logo $1,6 \mathrm{~kg}$ equivaleu a um custo energético gestacional requerido para treze semanas (primeiro trimestre) de $10240 \mathrm{kcal}$. Posteriormente, esse valor foi fracionado por noventa e um dias (número de dias correspondente ao primeiro trimestre gestacional), resultando em um adicional energético diário de 112,52kcal, o qual foi somado juntamente às $40 \mathrm{kcal}$ originárias do adicional proteico diário de $6 \mathrm{~g}$ (corrigidos para $10 \mathrm{~g}$, considerando dieta mista brasileira à base de carnes e cereais), preconizado pela FAO/OMS ${ }^{11}$, com o GE pré-gestacional de $2035 \mathrm{kcal}$, já anteriormente calculado, resultando em um Valor Energético Total (VET) diário de $2188 \mathrm{kcal}$ para esse trimestre gestacional.

b) Para o cálculo do adicional energético do segundo e terceiro trimestres gestacionais, seguiu-se também a recomendação de ganho ponderal estabelecida pelo $\mathrm{IOM}^{8}$, que é de $0,4 \mathrm{~kg} /$ semana a partir do segundo trimestre de gravidez, não devendo, no entanto, o ganho ponderal semanal ultrapassar $0,5 \mathrm{~kg}^{21}$. Dessa maneira, como o ganho de peso total médio proposto para a gestante referência foi de $13,75 \mathrm{~kg}$, os $12,15 \mathrm{~kg}$ complementares aos $1,6 \mathrm{~kg}$ (programados para serem ganhos no primeiro trimestre) devem ser obtidos no segundo e terceiro trimestres de gravidez. Portanto, a partir do segundo trimestre, que tem início na $14^{\mathrm{a}}$ semana gestacional, a gestante deve expressar um ganho ponderal de $0,46 \mathrm{~kg} /$ semana, que corresponderá a $12,15 \mathrm{~kg}$ ao término das vinte e seis semanas (182 dias) gestacionais restantes.

O cálculo da suplementação energética diária referente ao segundo e terceiro trimestres baseou-se nos mesmos critérios metodológicos usados na determinação do adicional energético para o primeiro trimestre. $\mathrm{O}$ ganho de peso referente ao segundo e terceiro trimestres gestacionais $(12,15 \mathrm{~kg})$ correspondeu a um custo calórico total de 77 760kcal. A divisão desse valor por 182 dias (total de dias referente ao segundo e terceiro trimestres gestacionais) gerou um adicional energético diário de $427 \mathrm{kcal}$, o qual foi somado juntamente às $40 \mathrm{kcal}$ originárias do adicional proteico diário corrigido de $10 \mathrm{~g}$ preconizado pela FAO/OMS ${ }^{11}$, com o GE pré-gestacional de $2035 \mathrm{kcal}$, totalizando em um VET de $2502 \mathrm{kcal}$ para o segundo e terceiro trimestres gestacionais.

O terceiro passo consistiu na elaboração dos planos alimentares, que foram dispostos em seis refeições (desjejum, lanche da manhã, almoço, lanche da tarde, jantar e lanche da noite), detalhando-se os aspectos referentes aos grupos alimentares, tamanho das porções, peso em gramas e medidas caseiras segundo os níveis propostos na pirâmide, conforme Philippi et al. ${ }^{17,18}$.

Para a distribuição percentual dos macronutrientes em relação aos planos alimentares de $2188 \mathrm{kcal}$ e $2502 \mathrm{kcal}$ estabelecidos para o primeiro e os demais trimestres gestacionais, respectivamente, seguiu-se a recomendação de $1 \mathrm{~g}$ de proteína/kg de peso corporal pré-gestacional/ dia (para indivíduos adultos) da FAO/OMS/UNU ${ }^{11}$ com acréscimo do adicional proteico corrigido de $10 \mathrm{~g}^{11}$. A distribuição percentual de carboidratos e lipídeos baseou-se também nas recomendações da $\mathrm{FAO} / \mathrm{OMS}^{10}$. Assim, adotaram-se as distribuições percentuais, a saber: carboidratos (55\% a $75 \%$ ) e lipídios (15\% a 30\%) ${ }^{10}$, tendo esse último obedecido à classificação preconizada pela Organização Mundial de Saúde ${ }^{10}$ quanto à quantidade de colesterol ( $<300 \mathrm{mg} / \mathrm{dia})$ e à qualidade dos ácidos graxos saturados $(<10 \%)$, poliinsa- 
turados (até 10\%), monoinsaturados $(10 \%$ a $15 \%)$ e trans (<1\%). Em relação aos carboidratos, considerou-se ainda a recomendação de até 10\% para sacarose e de $25 \mathrm{~g} /$ dia para as fibras ${ }^{10}$. Para a distribuição percentual do VET por refeições, utilizou-se a recomendação proposta por Fausto22.

O cálculo dos planos alimentares foi realizado utilizando-se o software "Virtual Nutri", desenvolvido pelo Departamento de Nutrição da Universidade de São Paulo ${ }^{23}$, conforme metodologia de Philippi et al..1718. Esses planos alimentares foram elaborados tendo como base alimentos típicos do hábito alimentar dos brasileiros.

O desenho de pirâmide alimentar proposto para gestantes eutróficas entre 19 e 30 anos de idade foi elaborado com base nos planos alimentares padrões calculados para essa faixa etária. Seguindo as diretrizes preconizadas no Guia Alimentar para a População Brasileira do Ministério da Saúde ${ }^{16}$, o desenho contém os alimentos mais consumidos pela população brasileira ${ }^{24}$ e foi inspirado no modelo da pirâmide alimentar proposto por Philippi et al. ${ }^{17}$. As porções recomendadas no corpo do modelo da pirâmide foram estabelecidas em função dos grupos alimentares, a saber: cereais, hortaliças, frutas, leite, carnes e ovos, leguminosas, açúcares e gorduras. Assim, com base nas necessidades nutricionais e recomendações, optou-se por desenvolver o modelo intitulado: Pirâmide alimentar para gestantes eutróficas de 19 a 30 anos.

Optou-se pelo modelo da pirâmide alimentar, considerando-se o êxito experimentado na sua utilização e indicação para orientação nutricional de outros ciclos de vida ${ }^{17,18,25}$. Esse modelo é destinado às gestantes eutróficas de
19 a 30 anos de idade e tem foco na gestação a termo. O modelo apresenta o primeiro trimestre da gravidez isoladamente e o segundo e o terceiro trimestres, conjuntamente.

Para a determinação do tamanho das porções, seguiu-se os parâmetros estabelecidos por Philippi et al. ${ }^{17}$ e disponíveis no anexo $\mathrm{C}$ do guia alimentar para a população brasileira ${ }^{16}$. Já para a obtenção do número de porções/dia de cada grupo de alimentos, levou-se em consideração a necessidades nutricionais demandadas em cada trimestre de gestação ${ }^{2,11}$.

Assim, o número de porções colocado na pirâmide alimentar da gestante eutrófica referente aos trimestres gestacionais foi encontrado em obediência aos valores energéticos dos planos alimentares relativos ao primeiro, segundo e terceiro trimestres gestacionais e em acordo com o valor calórico de cada grupo de alimentos disponível nos anexos B e $C$ do guia alimentar para a população brasileira ${ }^{16}$.

\section{RES U L T A D OS}

A Tabela 1 apresenta o valor energético por trimestre e a distribuição percentual dos macronutrientes. Nessa distribuição, todos os macronutrientes estão dentro dos intervalos preconizados $^{10}$.

Os planos alimentares padrões elaborados conforme necessidades energéticas estimadas para o primeiro trimestre e para o segundo e terceiros trimestres gestacionais são representados nas tabelas 2 e 3, respectivamente. No Anexo apresenta-se uma lista de alimentos substitutos por porção segundo os grupos de alimentos para ambos os planos alimentares.

Tabela 1. Valor energético ( $\mathrm{kcal}$ ) e distribuição percentual (\%) dos macronutrientes dos planos alimentares de acordo com os trimestres gestacionais.

\begin{tabular}{lcccc}
\hline \multirow{2}{*}{ Plano alimentar (kcal) } & \multirow{2}{*}{ Trimestre de gestação (TG) } & \multicolumn{3}{c}{ \% de macronutrientes } \\
\cline { 2 - 5 } & & Proteínas & Carboidratos & Lipídeos \\
\hline 2188 & $1^{\circ}$ & 12,0 & 62,0 & 26,0 \\
2502 & $2^{\circ}$ e $3^{\circ}$ & 11,0 & 60,0 & 29,0 \\
\hline
\end{tabular}


Em relação à qualidade dos lipídeos, o percentual de ácidos graxos para o plano alimentar referente ao primeiro trimestre é de 8,0\% de poliinsaturados, $11,0 \%$ de monoinsaturados e $7,0 \%$ de saturados. Já para o plano alimentar do $2^{\circ}$ e $3^{\circ}$ trimestres, o percentual é de $5,0 \%$

Tabela 2. Plano alimentar padrão (2 188kcal) para gestantes eutróficas no $1^{\circ}$ trimestre de gravidez, com respectivos alimentos, grupos, porções, peso (gramas) e medidas caseiras.

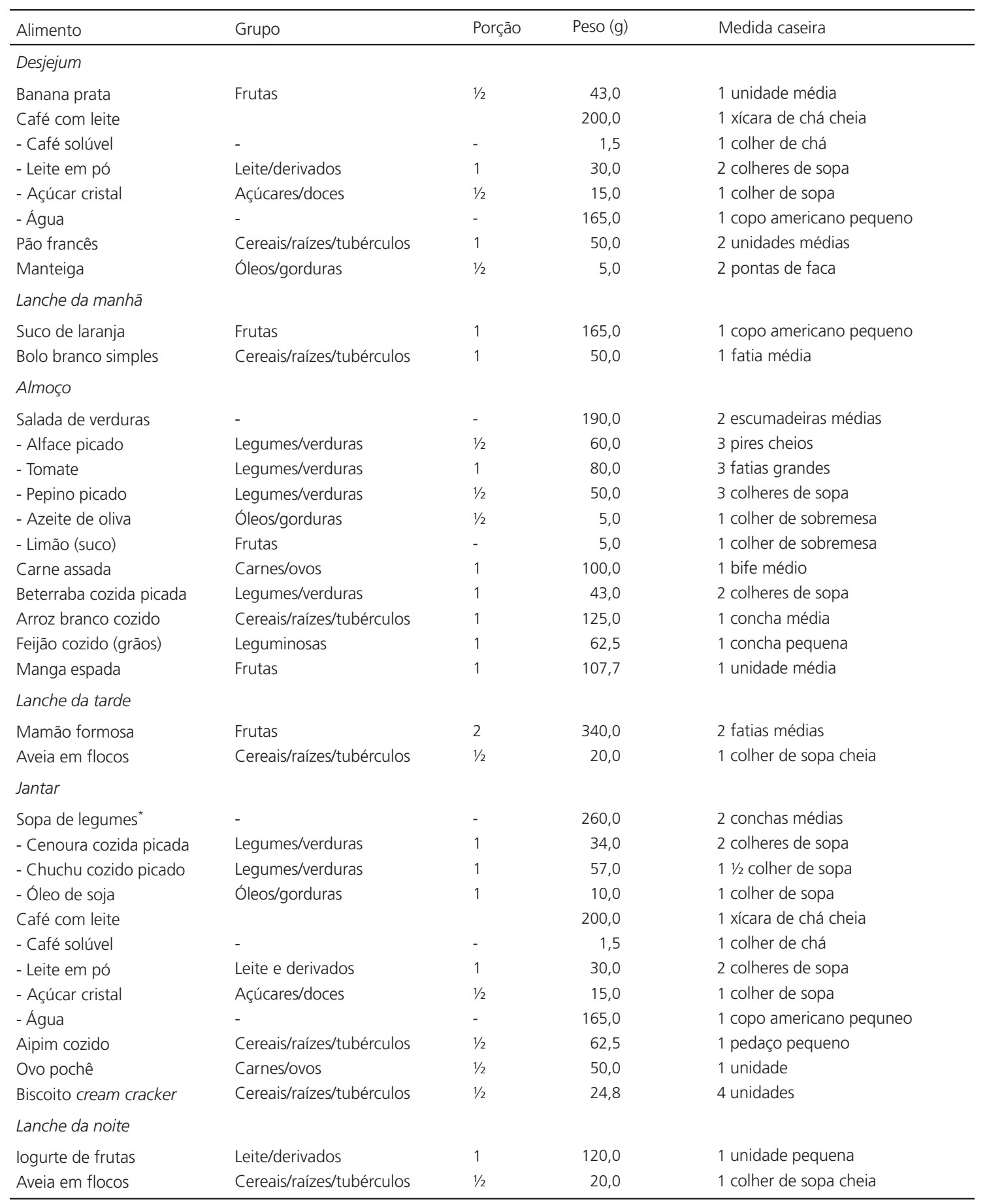

Energia total $=2194 \mathrm{kcal}$. Dados obtidos do software "Virtual Nutri"; * temperar a gosto.

A quantidade de óleo/gordura usada já está incluída nas preparações, estimada em $10 \mathrm{~g}$ óleo/dia. 
para os poliinsaturados, $10,0 \%$ de monoinsaturados e $6,5 \%$ de saturados. A quantidade de colesterol é de $293 \mathrm{mg}$ para ambos os planos alimentares.
No que se refere à qualidade dos carboidratos, o plano alimentar do $1^{\circ}$ trimestre e do $2^{\circ}$ e $3^{\circ}$ trimestres apresentam 9,0\% e 8,0\% de sacarose, respectivamente. As fibras perfazem um

Tabela 3. Plano alimentar padrão ( $2502 \mathrm{kcal})$ para gestantes eutróficas no $2^{\circ}$ e $3^{\circ}$ trimestres de gravidez, com respectivos alimentos, grupos, porções, peso (gramas) e medidas caseiras.

\begin{tabular}{|c|c|c|c|c|}
\hline Alimento & Grupo & Porção & Peso (g) & Medida caseira \\
\hline \multicolumn{5}{|l|}{ Desjejum } \\
\hline Banana prata & Frutas & $1 / 2$ & 43,0 & 1 unidade média \\
\hline Café com leite & & & 200,0 & 1 xícara de chá cheia \\
\hline - Café solúvel & - & - & 1,5 & 1 colher de chá \\
\hline - Leite em pó & Leite/derivados & 1 & 30,0 & 2 colheres de sopa \\
\hline - Açúcar cristal & Açúcares/doces & $1 / 2$ & 15,0 & 1 colher de sopa \\
\hline - Água & - & - & 165,0 & 1 copo americano pequeno \\
\hline Pão francês & Cereais/raízes/tubérculos & 1 & 50,0 & 2 unidades médias \\
\hline Biscoito cream cracker & Cereais/raízes/tubérculos & $1 / 2$ & 24,8 & 4 unidades \\
\hline Manteiga & Óleos/gorduras & $1 / 2$ & 5,0 & 2 pontas de faca \\
\hline \multicolumn{5}{|l|}{ Lanche da manhã } \\
\hline Suco de laranja & Frutas & 1 & 165,0 & 1 copo americano pequeno \\
\hline Bolo branco simples & Cereais/raízes/tubérculos & 1 & 50,0 & 1 fatia média \\
\hline \multicolumn{5}{|l|}{ Almoço } \\
\hline Salada de verduras & - & - & 190,0 & 2 escumadeiras médias \\
\hline - Alface picado & Legumes/verduras & $1 / 2$ & 60,0 & 3 pires cheios \\
\hline - Tomate & Legumes/verduras & 1 & 80,0 & 3 fatias grandes \\
\hline - Pepino picado & Legumes/verduras & $1 / 2$ & 50,0 & 3 colheres de sopa \\
\hline - Azeite de oliva & Óleos/gorduras & 1 & 10,0 & 1 colher de sopa \\
\hline - Limão (suco) & Frutas & - & 5,0 & 1 colher de sobremesa \\
\hline Carne assada & Carnes/ovos & 1 & 100,0 & 1 bife médio \\
\hline Beterraba cozida picada & Legumes/verduras & 1 & 43,0 & 2 colheres de sopa \\
\hline Arroz branco cozido & Cereais/raízes/tubérculos & 1 & 125,0 & 1 concha média \\
\hline Feijão cozido (grãos) & Leguminosas & 1 & 62,5 & 1 concha pequena \\
\hline Manga espada & Frutas & 1 & 107,7 & 1 unidade média \\
\hline \multicolumn{5}{|l|}{ Lanche da tarde } \\
\hline Mamão formosa & Frutas & 2 & 340,0 & 2 fatias médias \\
\hline Aveia em flocos & Cereais/raízes/tubérculos & $1 / 2$ & 20,0 & 1 colher de sopa cheia \\
\hline \multicolumn{5}{|l|}{ Jantar } \\
\hline Sopa de legumes ${ }^{*}$ & - & - & 260,0 & 2 conchas médias \\
\hline - Cenoura cozida picada & Legumes/verduras & 1 & 34,0 & 2 colheres de sopa \\
\hline - Chuchu cozido picado & Legumes/verduras & 1 & 57,0 & $11 \frac{1}{2}$ colher de sopa \\
\hline - Óleo de soja & Óleos/gorduras & 1 & 10,0 & 1 colher de sopa \\
\hline Café com leite & & & 200,0 & 1 xícara de chá cheia \\
\hline - Café solúvel & - & - & 1,5 & 1 colher de chá \\
\hline - Leite em pó & Leite e derivados & 1 & 30,0 & 2 colheres de sopa \\
\hline - Açúcar cristal & Açúcares/doces & $1 / 2$ & 15,0 & 1 colher de sopa \\
\hline - Água & - & - & 165,0 & 1 copo americano pequeno \\
\hline Aipim cozido & Cereais/raízes/tubérculos & 2 & 225,0 & 2 pedaços médios \\
\hline Ovo pochê & Carnes/ovos & $1 / 2$ & 50,0 & 1 unidade \\
\hline \multicolumn{5}{|l|}{ Lanche da noite } \\
\hline logurte de frutas & Leite/derivados & 1 & 120,0 & 1 unidade pequena \\
\hline Aveia em flocos & Cereais/raízes/tubérculos & $1 / 2$ & 20,0 & 1 colher de sopa cheia \\
\hline
\end{tabular}

Energia total = $2487 \mathrm{kcal}$. Dados obtidos do software "Virtual Nutri"; * temperar a gosto.

A quantidade de óleo/gordura usada já está incluída nas preparações, estimada em $10 \mathrm{~g}$ óleo/dia. 
total de $25,4 \mathrm{~g}$ para o primeiro trimestre e de $27,7 \mathrm{~g}$ para os demais trimestres gestacionais.

A pirâmide alimentar da gestante eutrófica é, então, dividida em quatro níveis e os alimentos estão organizados em oito grupos alimentares e porcionados de acordo com as necessidades energéticas determinadas para o primeiro, segundo e terceiro trimestres gestacionais (Figura 1).

Primeiro nível: é constituído pelo grupo alimentar dos cereais (arroz, pão, massa, cuscuz, bolo, biscoito, etc.), raízes (aipim, inhame) e tubérculos (batata-doce): os alimentos desse grupo são as melhores fontes de carboidrato comple$\mathrm{xo}$, nutriente que contribui expressivamente com a maior parte do valor energético da dieta - recomenda-se a ingestão de 5 porções/dia no primeiro trimestre e $61 / 2$ porções/dia no segundo e terceiro trimestres de gestação.
Segundo nível: constituído pelo grupo dos legumes e verduras e das frutas: os alimentos pertencentes a esses grupos são excelentes fontes de vitaminas, minerais e fibras - recomendam-se 5 porções/dia de legumes/verduras e 411/2 porções/ dia de frutas no primeiro, segundo e terceiro trimestres.

Terceiro nível: formado pelo grupo do leite e derivados (iogurtes, queijos, etc.), que são boas fontes de cálcio, proteína e vitamina - recomendam-se três porções/dia durante todo o período gestacional; grupo das carnes e ovos, alimentos fontes de proteína e ferro biodisponível, inclui carne bovina, suína, caprina, aves, peixes, frutos do mar, vísceras e ovos - recomenda-se 11/2 porção/dia para todo o período de gestação; grupo das leguminosas: engloba os feijões, soja, ervilha, grão de bico, lentilha e sementes oleagi-

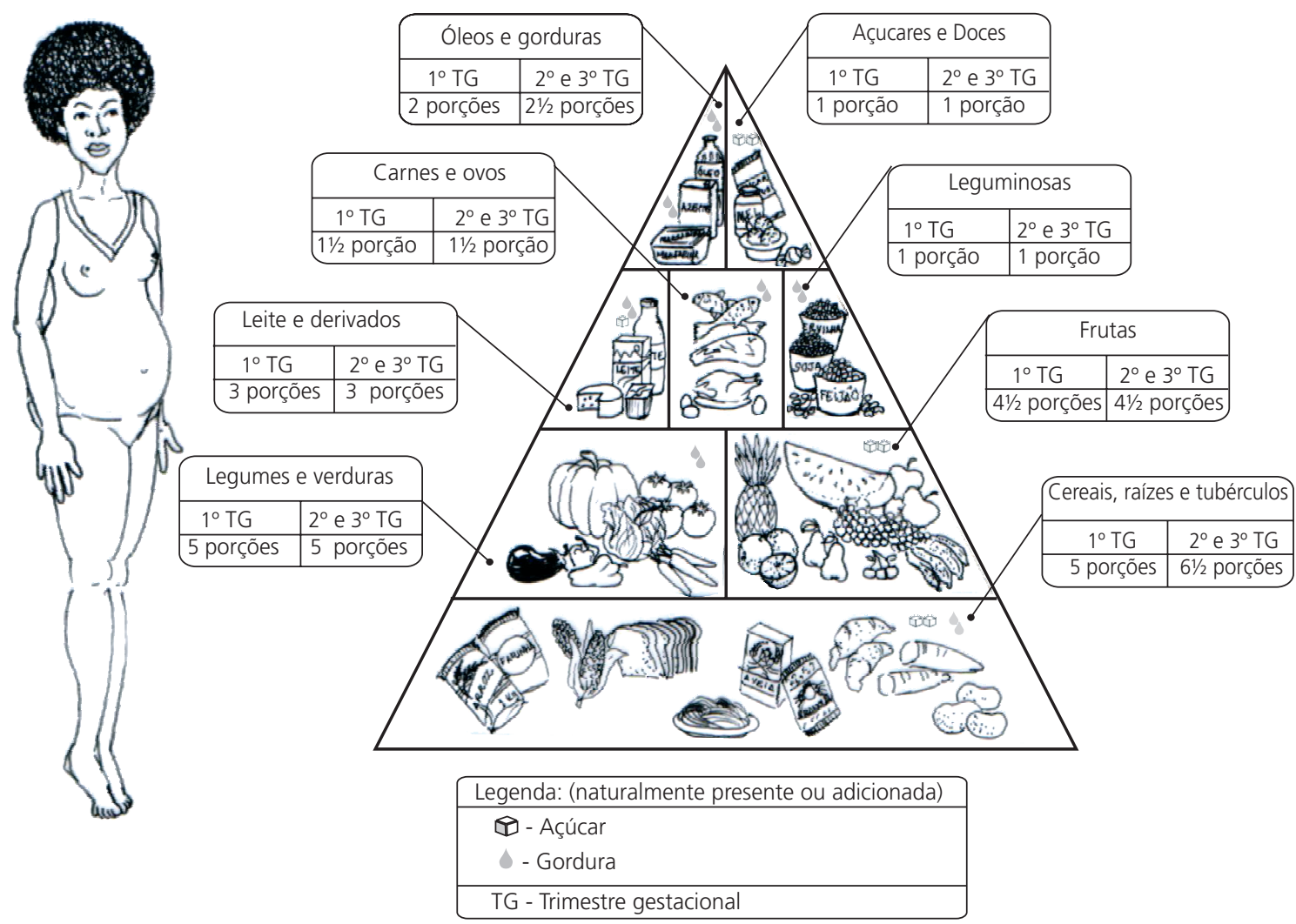

Figura 1. Pirâmide alimentar adaptada para gestantes eutróficas de 19 a 30 anos.

Fonte: Demétrio, $\mathrm{F}$.

llustração: Fernando Souza.

Finalização computação gráfica: Wesley Santos.

Dados de porções: Anexo C do guia alimentar para população brasileira. 
nosas, que são fontes de proteína vegetal, minerais e fibra - recomenda-se 1 porção/dia no decurso de toda a gestação.

Quarto nível: grupo dos óleos e gorduras (óleo, manteiga, margarina, banha): alimentos fontes de lipídeos, nutriente de função energética no organismo e presente nas mais diversas preparações alimentares - recomendam-se 2 porções/dia no primeiro trimestre e $2 \frac{1}{2}$ porções/dia no segundo e terceiro trimestres; grupo dos açúcares e doces (doces, mel e açúcares): constituídos por carboidratos simples (a exemplo da sacarose) e de elevado índice glicêmico. Devem ser consumidos com moderação, pois além de se encontrar no topo da pirâmide, fazem-se presentes nas mais diversas preparações alimentares - recomenda-se o consumo de 1 porção/dia em toda a gestação.

Quanto à distribuição calórica por refeições, no primeiro trimestre, $20 \%$ do VET diário se concentrou no desjejum, $30 \%$ no almoço e $26 \%$ no jantar. O restante foi disposto entre os lanches intermediários, sendo cerca de 8\% para cada um. No plano alimentar do segundo e terceiro trimestres de gestação, 19\% do VET se concentrou no desjejum, $32 \%$ no almoço e $28 \%$ no jantar. Os percentuais restantes foram distribuídos entre os lanches intermediários, sendo aproximadamente $7 \%$ para cada um.

Algumas recomendações básicas, fundamentadas nas diretrizes para a promoção de práticas alimentares saudáveis voltadas para a população brasileira ${ }^{16} \mathrm{e}$ visando complementar as orientações nutricionais e gerais para as gestantes eutróficas, são sugeridas: escolher uma dieta variada com alimentos de todos os grupos da pirâmide e evitar a monotonia alimentar; preferir os vegetais: frutas, legumes e verduras; atentar para a forma de preparo dos alimentos, dando preferência às formas in natura ou de preparação assada, cozida em água ou ao vapor, ou grelhada; procurar fazer a leitura dos rótulos dos alimentos industrializados para conhecer seu valor nutricional e seu modo de preparo; incluir os alimentos da base da pirâmide em maior quantidade na ali- mentação diária; usar açúcares, doces, sal e alimentos com elevados teores de sódio com cautela; consumir alimentos com baixo teor de gordura saturada (carnes magras) e usar fontes de gorduras mono e poliinsaturadas (óleos vegetais, castanha, amendoim, amêndoa, nozes, linhaça, gergelim, etc.); ingerir de 6 a 8 copos de água diariamente; realizar exposição frequente ao sol (antes das 10 horas e após as 16 horas); evitar o consumo de álcool; buscar acompanhamento médico e nutricional desde o início da gravidez como forma de garantir uma gestação sem intercorrências.

\section{DIS CUSS Ã O}

O número de porções recomendado na pirâmide alimentar para gestantes eutróficas situa-se dentro dos valores preconizados pelo guia alimentar para a população brasileira ${ }^{16}$ e por Philippo et al..$^{17}$ no que se refere à maioria dos grupos de alimentos, com exceção do grupo de óleos e gorduras referente ao $2^{\circ}$ e $3^{\circ}$ trimestres gestacionais, cujo número de porções se mostrou maior quando comparado ao que é aconselhado para adultos saudáveis.

A recomendação do grupo de óleos e gorduras é aumentada no segundo e terceiro trimestres de gestação por conta de haver nesse período modificações no metabolismo de energia da gestante, tais como diminuição da demanda de glicose e aumento da utilização de ácidos graxos como fonte de energia ${ }^{26}$. Além disso, outra modificação importante evidenciada a partir desse período é a maior deposição de gordura no organismo materno, como mecanismo de reserva energética para a fase lactacional ${ }^{26,2}$. Observa-se ainda elevação dos níveis plasmáticos de ácidos graxos, triglicerídeos e lipoproteínas, principalmente a Lipoproteína de Baixa Densidade (LDL), para atender às demandas fetais e à produção de hormônios esteróides maternos relacionados às modificações fisiológicas da gravidez ${ }^{26}$. Contudo, atentou-se para uma recomendação dietética de lipídeos em uma proporção maior de poliin- 
saturados (contemplam os ácidos graxos essenciais linoléico e linolênico) e monoinsaturados em detrimento dos saturados e trans, uma vez que o consumo aumentado de ácidos graxos trans durante a gestação está associado com risco elevado de pré-eclâmpsia, retardo do crescimento intrauterino, baixo peso ao nascer, redução da circunferência cefálica e início do processo de aterogênese ainda na fase intrauterina ${ }^{27}$.

Durante a gravidez, sobretudo a partir da $20^{a}$ semana gestacional, ocorre menor utilização periférica de glicose associada com ineficácia da ação insulínica, devido à redução da sensibilidade à insulina materna pela ação dos hormônios contrainsulínicos hPL, hGH, estrogênio, progesterona, cortisol, prolactina e glucagon ${ }^{26}$. Esses ajustes metabólicos no organismo materno acontecem para atender as exigências fetais aumentadas de glicose e aminoácidos para seu crescimento e desenvolvimento ${ }^{26,2}$. Algumas gestantes conseguem compensar esse processo com aumento na produção pancreática de insulina. Porém aquelas gestantes com reserva pancreática limitada não conseguem alcançar a compensação e desenvolve a diabetes gestacional ${ }^{2}$. Nesse sentido, a quantidade de sacarose nos planos alimentares está em acordo com o valor preconizado ${ }^{10}$ e, portanto, não contribui para elevações bruscas da glicemia materna.

Ressalta-se ainda que na gravidez há hipotonia do sistema gastrointestinal devido à ação hormonal da progesterona, que, de um lado, ocasiona maior tempo de esvaziamento gástrico, maior ocorrência de náuseas, pirose e obstipação intestinal e, de outro, proporciona maior tempo de contato entre os nutrientes e a mucosa absortiva, levando ao aumento da absorção dos nutrientes e água, favorecendo, dessa maneira, o anabolismo ${ }^{2,26}$. Considerando esses aspectos, é importante o fracionamento alimentar diário em seis refeições e o consumo adequado de fibras e água, conforme é proposto neste trabalho.

No que diz respeito à distribuição percentual do VET por refeições, referente tanto ao primeiro quanto ao segundo e terceiro trimestres gestacionais, é válido destacar que os percentuais relativos às refeições principais situam-se próximos daqueles recomendados para adultos sadios ${ }^{22}$. Já para os lanches intermediários, esses percentuais são maiores quando comparados aos recomendados para adultos, pois se levaram em consideração as alterações fisiológicas no organismo materno, cujos níveis de glicemia depois de um período de jejum geralmente são 15\% a 20\% menores em relação aos níveis observados no período não gravídico². Desse modo, estar-se-á contribuindo para minimizar lipólise e prevenir cetoacidose materna, uma vez que os corpos cetônicos produzidos em demasia podem causar lesão neurológica no feto 2,26.

Cabe ressaltar também que cerca de $50 \%$ das gestantes apresentam náuseas, principalmente no $1^{\circ}$ trimestre, ocorrendo, principalmente pela manhã, devido às elevações dos níveis de estrógeno na gravidez, sendo muitas vezes acompanhadas por vômitos e anorexia, podendo comprometer seu estado nutricional ${ }^{2,26}$. Assim, a gestante deve ser aconselhada a fracionar adequadamente a dieta, a reduzir o consumo de gorduras e o volume da refeição, a preferir o consumo de alimentos mais sólidos e a aumentar a ingestão hídrica.

Em relação à presença e à necessidade de guias alimentares para a população, observa-se que a discussão sobre seu uso e adequação nos países da América Latina, assim como a necessidade de desenvolvê-los e implementá-los, é ainda um processo novo. Os estudos que abordam esse aspecto tiveram sua origem a partir de 1992, com a Conferência Mundial de Nutrição em Roma ${ }^{17}$. Alguns países, a exemplo do México e da Venezuela, desde 1994, já possuem seus guias alimentares para a população adulta saudável. Outros como Chile, Guatemala e Costa Rica ainda estão em fase de validação ${ }^{17}$.

O Brasil, recentemente, oficializou seu guia alimentar para sua população adulta ${ }^{16}$. Sente-se falta, no entanto, de guia para grupos populacionais biologicamente vulneráveis, a exemplo da gestante ${ }^{1}$, e de uma apresentação de mais fácil 
compreensão, com adaptações dos conteúdos, das mensagens e das porções de alimentos compatíveis com a situação fisiológica do grupo. Dessa maneira, essa ferramenta será de fácil uso nos serviços de saúde, em especial nas esferas do Sistema Único de Saúde (SUS), sobretudo como um componente estimulador da adoção de práticas alimentares saudáveis nesse ciclo da vida.

De acordo com Assis et al.28, o perfil de morbidade da gestante brasileira tem se caracterizado pela dualidade do estado de nutrição e saúde, segmentando-se entre aquele representado pelo déficit do estado antropométrico ao gestar, decorrendo em baixo peso ao nascer, e as consequências negativas para a sobrevivência do recém-nascido, e pelo excesso ponderal, associado às doenças cardiovasculares, diabetes mellitus, obesidade e macrossomia, os quais se constituem em riscos elevados de morbimortalidade materno-infantil.

Rocha et al. ${ }^{3}$, ao estudarem o estado nutricional de gestantes no Estado de Minas Gerais, avaliaram o peso pré-gestacional e o ganho de peso durante a gestação. Os resultados indicaram que entre o grupo de gestantes de baixo peso, quase $60,0 \%$ apresentaram ganho de peso insuficiente e $18,6 \%$ ganho excessivo de peso até o momento da avaliação. Entre o grupo de gestantes eutróficas, 51,6\% apresentaram reduzido ganho de peso e $26,3 \%$ elevado ganho de peso gestacional. No grupo das gestantes com sobrepeso e obesidade, a maior parte $(48,3 \%)$ teve um ganho de peso excessivo.

Esses achados reforçam a necessidade do desenvolvimento de ações contínuas voltadas para a vigilância e atenção alimentar e nutricional das gestantes.

No Brasil, as ações de atenção alimentar e nutricional no pré-natal estão previstas no cenário da Política Nacional de Alimentação e Nutrição (PNAN), destacando-se temas que privilegiam informações quanto à prática da alimentação saudável, com foco na prevenção dos distúrbios nutricionais e das doenças associadas à alimen- tação e à nutrição - baixo peso, sobrepeso, obesidade, hipertensão e diabetes; deficiência de ácido fólico, ferro e iodo, carências reconhecidas como de consequência grave para o feto ${ }^{12,3,5}$.

Destarte, o enfoque prioritário conferido para a questão da segurança alimentar e nutricional em nível das políticas públicas em âmbito federal e pelos governos e sistemas locais constitui fator de sucesso de qualquer programa de prevenção, promoção, intervenção e atenção integral à saúde ${ }^{10,16}$. Desse modo, o Brasil experimenta um cenário político extremamente favorável para a produção de conhecimentos e instrumentos de assistência alimentar e nutricional, uma vez que a segurança alimentar e nutricional ocupa na atualidade o topo da agenda nacional de saúde ${ }^{16}$.

Nesse sentido, a pirâmide alimentar adaptada para gestantes eutróficas, com base nas diretrizes do guia alimentar para a população brasileira ${ }^{16}$, pode ser capaz de guiá-las quanto à manutenção e/ou aquisição de hábitos alimentares saudáveis durante todo o período gestacional e exercer impacto positivo no resultado da gestação, bem como na qualidade de vida materna. Dessa maneira, reduzir-se-á a possibilidade/ risco da gestante em início de gravidez, eutrófica, vir a apresentar, no transcorrer da gestação, estado nutricional de baixo peso ou sobrepeso/obesidade. Destaca-se que o guia alimentar proposto neste estudo necessita de validação e implementação, etapas enfaticamente preconizadas pelos organismos internacionais.

\section{O N CLUS Ã O}

A pirâmide alimentar proposta neste estudo é um instrumento educativo, de cunho metodológico e de caráter prático, voltado para a atenção alimentar e nutricional de gestantes eutróficas na faixa etária de 19 a 30 anos. Seu uso pode ser capaz de despertar o interesse pela adoção de práticas alimentares saudáveis, preservando o padrão socioeconômico, cultural e regional ligados à alimentação, contribuindo, assim, para uma gestação que redunde na manutenção da saúde materna e fetal. 
A representação gráfica em forma de pirâmide sugerida neste estudo consiste em um material que traduz de maneira quali-quantitativa as recomendações nutricionais para orientação alimentar e nutricional da gestante eutrófica. Esse material pode resultar em mecanismo capaz de manter o seu adequado estado de nutrição e saúde e de reduzir a ocorrência de baixo peso ao nascer, prematuridade e macrossomia.

A pirâmide alimentar para gestantes eutróficas de 19 a 30 anos poderá ser colocada à disposição dos profissionais de saúde, em especial daqueles que estão inseridos no âmbito do SUS, e deve ser entendida, sobretudo, como um instrumento metodológico com caráter educativo e estimulador da adoção da alimentação saudável nesse ciclo da vida.

\section{A GRADECIMENTOS}

À Professora Dra. Ana Marlúcia Oliveira Assis pela valiosa contribuição na orientação e revisão crítica deste trabalho; às Professoras Valterlinda Alves de Oliveira Queiroz e Mônica Leila Portela de Santana pelas relevantes sugestões; e ao Centro Colaborador em Alimentação e Nutrição Região Nordeste II (CECAN-II)/ Ministério da Saúde pelo suporte técnico-científico.

\section{REFERÊ N CIAS}

1. King JC. Physiology of pregnancy and nutrient metabolism. Am J Clin Nutr. 2000; 71(5):1218S-25S.

2. Accioly E, Saunders C, Lacerda EMA. Nutrição em obstetrícia e pediatria. Rio de Janeiro: Cultura Médica; 2002.

3. Rocha DS, Netto MP, Priori SE, Lima NMM, Rosado LEFPL, Franceschini SCC. Estado nutricional e anemia ferropriva em gestantes: relação com o peso da criança ao nascer. Rev Nutr. 2005; 18(4):4181-9. doi: 10.1590/S1415-52732005000400004.

4. Hassan Gl, Onu AB. Concentração total de vitamina $C$ na gestante: implicações para uma gestação saudável. Rev Bras Saúde Matern Infant. 2006; 6(3): 293-6.

5. Pacheco SS, Souza Al, Vidal SA, Guerra GVQL, Batista Filho M, Baptista EVP, Melo MIB. Prevalência dos defeitos de fechamento do tubo neural em recém-nascidos do Centro de Atenção à Mulher do Instituto Materno Infantil Prof. Fernando Figueira, IMIP: 2000-2004. Rev Bras Saúde Matern Infant. 2006; 6(Supl. 1):535-42.

6. International Food Information Council Foundation. Healthy eating during pregnancy. 2003 [acesso 2007 abr. 22]. Disponível em: <http://www.ific.org/ publications/brochures/pregnancybroch.cfm>.

7. Oken E, Gillman MW. Fetal origins of obesity. Obes Res. 2003; 11(4):496-506.

8. Institute of Medicine. National Academy of Sciences. Nutrition during pregnancy and lactation. an implementation guide. Washington: National Academy Press; 1992.

9. Merlino A, Laffineuse L, Collin M, Mercer B. Impact of weigth loss between pregnancies on recurrent preterm birth. Am J Obstet Gynecol. 2006; 195(3): 818-21.

10. World Health Organization. Diet, nutrition and the prevention of chronic diseases. Report of a Joint WHO/FAO Expert Consultation. Geneva: WHO; 2003. WHO Technical Report Series.

11. Organização Mundial da Saúde. Necessidades de energia e de proteínas. São Paulo: Roca; 1998.

12. Brasil. Ministério da Saúde. Pré-Natal e puerpério: atenção qualificada e humanizada - manual técnico. Brasília: Ministério da Saúde; 2005.

13. Bocardi MIB. Assistência pré-natal na adolescência: concepções das adolescentes e dos profissionais de saúde [dissertação]. São Paulo: Universidade de São Paulo; 2004.

14. Abu-Heija AT, Jallad MF, Abukteish F. Maternal and perinatal outcome of pregnancy after age of 45 . J Obstet Gynaecol Res. 2000; 26(1):27-30.

15. Nucci LB, Schmidt MI, Duncan BB, Fuchs SC, Fleck ET, Britto MMS. Nutritional status of pregnant women: prevalence and associated pregnancy outcomes. Rev Saúde Pública. 2001; 35(6):502-7.

16. Brasil. Ministério da Saúde. Guia alimentar para a população brasileira: promovendo a alimentação saudável: normas e manuais técnicos. Brasília: Ministério da Saúde; 2006.

17. Philippi ST, Latterza AR, Cruz ATR, Ribeiro LC. Pirâmide alimentar adaptada: guia para escolha dos alimentos. Rev Nutr. 1999; 12(1):65-80. doi: 10.15 90/S1415-52731999000100006.

18. Philippi ST, Cruz ATR, Colucci ACA. Pirâmide alimentar para crianças de 2 a 3 anos. Rev Nutr. 2003; 16(1):5-19. doi: 10.1590/S1415-52732003000 100002.

19. Martins IS. Requerimentos de energia e nutrientes da população brasileira. Rev Saúde Pública. 1979; 13(Supl. 1):1-20. 
20. Sichieri R. Avaliação crítica das recomendações de energia. Rev Bras Epidemiol. 2002; 5(Supl. 1):56-8.

21. Lopes AC, Ribas MR, Júnior AG. Gravidez. In: Waitzberg DL. Nutrição oral, enteral e parenteral na prática clínica. $3^{a}$ ed. São Paulo: Atheneu, 2006.

22. Fausto MA. Planejamento de dietas e da alimentação. Rio de Janeiro: Revinter; 2003.

23. Philippi ST, Szarfarc SC, Latterza AR. Virtual Nutri [programa de computador]. Versão 1.0 for Windows. São Paulo: Universidade de São Paulo; 1996.

24. Instituto Brasileiro de Geografia e Estatística. Coordenação de Índices de Preços. Pesquisa de Orçamentos Familiares 2002-2003: primeiros resultados. Rio de Janeiro; 2004.

25. Lichtenstein $A H$, Rasmussen $H$, Yu WW, Epstein SR, Russel RM. Modified MyPyramid for older adults. J Nutr. 2008; 138(1):5-11.
26. Rezende J, Montenegro CAB. Obstetrícia fundamental. $9^{a}$ ed. Rio de Janeiro: Guanabara Koogan; 2003.

27. Carlson S, Thomas MC, Cook HW, Emken EA, Filer Júnior L. Trans fatty acids: infant and fetal development. Am J Clin Nutr. 1997; 66(3):717S- 36S.

28. Assis AMO, Santos SMC, Freitas MCS, Santos JM, Silva MCM. O programa Saúde da família: contribuições para uma reflexão sobre a inserção do nutricionista na equipe multidisciplinar. Rev Nutr. 2002; 15(3):255-66. doi: 10.1590/S1415-5273200 2000300001.

Recebido em: 9/1/2009

Versão final reapresentada em: 12/1/2010 Aprovado em: 31/5/2010 
ANEXO

LISTA DE ALIMENTOS SUBSTITUTOS POR PORÇÃO DE ACORDO COM OS GRUPOS ALIMENTARES

\begin{tabular}{|c|c|}
\hline Alimento & 1 porção \\
\hline \multicolumn{2}{|c|}{ Cereais, raízes e tubérculos (1 porção = 150kcal) ${ }^{*}$} \\
\hline Batata inglesa/doce cozida & $11 / 2$ unidade \\
\hline Biscoito maria/maisena & 7 unidades \\
\hline Biscoito doce integral & 4 unidades \\
\hline Biscoito salgado integral & 5 unidades do tipo cracker \\
\hline Bolo de chocolate simples & 1 fatia pequena \\
\hline Farinha de mandioca & 3 colheres de sopa \\
\hline Farinha de milho & 4 colheres de sopa \\
\hline Inhame & 3 e 1/2 colheres de sopa ou 1 rodela média \\
\hline Macarrão cozido (branco ou integral) & 4 colheres de sopa \\
\hline Pão de hot dog/milho & 1 unidade \\
\hline Pão integral & 2 fatias ou 1 unidade \\
\hline Pipoca & 2 e $1 / 2$ xícaras de chá \\
\hline \multicolumn{2}{|c|}{ Legumes e verduras $(1 \text { porção }=15 \mathrm{kcal})^{*}$} \\
\hline Abobrinha/abóbora cozida & 1 e $1 / 2$ colher de sopa \\
\hline Acelga cozida/crua & 2 e $1 / 2$ colheres de sopa/9 colheres de sopa \\
\hline Agrião/Escarola/Rúcula & 2 xícaras de chá \\
\hline Berinjela cozida & 3 fatias \\
\hline Beterraba cozida/crua ralada & 3 fatias/2 colheres de sopa \\
\hline Brócolis & 3 colheres de sopa \\
\hline Cenoura cozida/crua ralada & 2 e $1 / 2$ colheres de sopa/3 colheres de sopa \\
\hline Chuchu cozido & 2 e $1 / 2$ colheres de sopa \\
\hline Couve & 3 colheres de sopa \\
\hline Couve-flôr & 1 ramo médio \\
\hline Espinafre/Nagem & 2 colheres de sopa cheias \\
\hline Quiabo & 4 unidades \\
\hline Repolho cozido/cru & 6 colheres de sopa/ 5 colheres de sopa \\
\hline \multicolumn{2}{|c|}{ Frutas $(1 \text { porção }=70 \mathrm{kcal})^{*}$} \\
\hline Abacate & 1 colher de sopa rasa \\
\hline Abacaxi & 1 fatia fina \\
\hline Acerola & 1 xícara de chá \\
\hline Banana nanica/maçã & $1 / 2$ unidade \\
\hline Banana da terra & $1 / 2$ unidade pequena \\
\hline Caju & 1 unidade grande \\
\hline Jaca & 4 bagos sem caroço \\
\hline Laranja/Tangerina/Lima/Goiaba & 1 unidade pequena \\
\hline Maçã & $1 / 2$ unidade média \\
\hline Mamão papaia & $1 / 2$ unidade \\
\hline Manga rosa & $1 / 2$ unidade média \\
\hline Melancia/Melão & 1 fatia média \\
\hline Uva & $1 / 2$ cacho pequeno \\
\hline Suco de Tangerina/Goiaba (diluído) & 1 copo americano pequeno \\
\hline Suco de fruta/polpa sem açúcar & 1 copo americano pequeno \\
\hline \multicolumn{2}{|c|}{ Leguminosas $(1 \text { porção }=55 \mathrm{kcal})^{*}$} \\
\hline Andu & 1 e $1 / 2$ concha média \\
\hline Ervilha seca cozida & 2 e $1 / 2$ colheres de sopa ou 1 concha pequena \\
\hline Feijão cozido com caldo & 1 concha média \\
\hline Feijão branco & $11 / 2$ colher de sopa \\
\hline Feijão verde/Mangalô & 1 e $1 / 2$ concha média \\
\hline Grão de bico & $1 / 2$ concha pequena \\
\hline Lentilha cozida & 1 concha pequena rasa \\
\hline
\end{tabular}


778 | F. DEMÉTRIO

ANEXO

LISTA DE ALIMENTOS SUBSTITUTOS POR PORÇÃO DE ACORDO COM OS GRUPOS ALIMENTARES

Conclusão

\begin{tabular}{|c|c|}
\hline Alimento & 1 porção \\
\hline \multicolumn{2}{|c|}{ Carnes e ovos (1 porção = 190kcal $)^{*}$} \\
\hline Bife grelhado & 1 unidade média \\
\hline Carne cozida & 1 fatia \\
\hline Carne moída refogada & 5 colheres de sopa \\
\hline Frango & 2 coxas ou 2 sobrecoxas pequenas (sem pele) \\
\hline Frango assado inteiro ou cozido & 1 coxa ou 1 sobrecoxa grande \\
\hline Filé de frango grelhado & 1 unidade grande \\
\hline Filé de peixe cozido/peixe cozido & 2 unidades médias/1 porção média \\
\hline Fígado & 1 bife médio \\
\hline Lombo de porco assado & 1 fatia \\
\hline Ovo de codorna & 6 unidades \\
\hline \multicolumn{2}{|c|}{ Leite e derivados $(1 \text { porção }=120 \mathrm{kcal})^{*}$} \\
\hline Bebida láctea & 1 copo tipo requeijão \\
\hline logurte desnatado & 1 pote \\
\hline logurte de mel & 1 pote \\
\hline logurte natural & 1 copo tipo requeijão \\
\hline Leite integral líquido & 1 copo tipo requeijão \\
\hline Queijo prato/mussarela & 2 fatias \\
\hline Queijo minas frescal/ricota & 2 fatias \\
\hline \multicolumn{2}{|c|}{ Açúcares e doces (1 porção = 110kcal) ${ }^{*}$} \\
\hline Açúcar mascavo grosso & 1 e $1 / 2$ colher de sopa \\
\hline Achocolatado em pó & 1 colher de sopa \\
\hline Doce industrializado tipo goiabada & $1 / 2$ fatia \\
\hline Geléia comum & 1 e $1 / 2$ colher de sopa \\
\hline Melaço & 2 colheres de sopa \\
\hline Mel de abelha & 2 colheres de sopa \\
\hline Soverte industrializado/frutas & 1 bola pequena/1 bola média \\
\hline \multicolumn{2}{|c|}{ Óleos e gorduras $(1 \text { porção }=73 \mathrm{kcal})^{*}$} \\
\hline Azeite de dendê & 1 colher de sobremesa \\
\hline Manteiga de garrafa & $1 / 2$ colher de sopa \\
\hline Margarina & 1 colher de sopa \\
\hline Óleo canola/milho/girassol & 1 colher de sopa \\
\hline
\end{tabular}

*Valores obtidos por Philippi et al. ${ }^{17}$ e disponíveis no anexo C do guia alimentar para a população brasileira ${ }^{16}$. 